\title{
Perancangan Aplikasi Sistem Informasi Untuk Melacak Aliran Dana Infaq dan Sedekah Masjid
}

\author{
Irfan Muhammad Iqbal \\ Telkom University; \\ Email: irfanmiqbal@student.telkomuniversity.ac.id
}

\begin{abstract}
Masjid merupakan tempat bagi para umat muslim untuk melakukan ibadah. Selain beribadah masjid juga merupakan tempat bagi umat muslim untuk beramal dengan memberikan sedekah atau infaq. Dana dari sumbangan dan infaq ini, dikelola oleh ta'mir atau pengurus masjid untuk kebutuhan operasional masjid dan menjadi dana untuk kegiatan program masjid. Dana yang tersisa biasanya diberikan kepada yang pihak yang membutuhkan. Namun sering kali kita tidak mengetahui secara rinci kemana dana infaq dan sedekah tersebut dialokasikan. Kita tidak mengetahui apakah dana tersebut sudah dibagikan kepada yang benar-benar membutuhkan, sehingga dikhawatirkan dana tersebut tidak tersebar merata. Aplikasi amal tracker merupakan aplikasi basis data yang dapat digunakan oleh ta'mir untuk mencatat pemasukan atau pengeluaran dari sumbangan yang masuk, dan kemanakah dana tersebut dialokasikan. Dan pengguna yang lain dapat melihat hasil laporan yang telah dicatat, sehingga dapat diketahui dengan jelas kemana aliran dana tersebut dialokasikan
\end{abstract}

Keywords: waterfall, aplikasi, sistem informasi, amal tracker

Paper ini akan dipublikasikan di osf.io [1] menggunakan format standard perancangan sistem informasi [2]

\section{Introduction}

1.1. Business case

a. Project Definition

Masjid sering menjadi tempat untuk para jama'ah untuk beramal dengan memberikan sedekah atau infaq. Dana sedekah atau infaq yang diterima oleh masjid melalui kotak sumbangan yang diedarkan atau tersedia di masjid yang bisa diisi kapan saja atau pada saat diedarkan Ketika berlangsung shalat jum'at atau shalat berjamaah lainnya. Dana dari sumbangan dan infaq ini, dikelola oleh ta'mir atau pengurus masjid untuk kebutuhan operasional masjid dan menjadi dana untuk kegiatan program masjid seperti kajian, ceramah, membagi makanan berbuka puasa dan lain-lain. Dana yang tersisa biasanya diberikan kepada pihak yang membutuhkan. Namun sering kali kita sebagai jamaah tidak mengetahui secara rinci kemana dana infaq dan sedekah tersebut dialokasikan. Kita tidak mengetahui apakah dana tersebut sudah dibagikan kepada yang benar-benar membutuhkan. Maka dibutuhkan aplikasi basis data yang dapat digunakan oleh ta'mir untuk mencatat pemasukan atau pengeluaran dari sumbangan yang masuk, dan kemanakah dana tersebut dialokasikan. Dan pengguna yang lain dapat melihat hasil laporan yang telah dicatat, sehingga dapat diketahui dengan jelas kemana aliran dana tersebut dialokasikan.

b. Project Objective 
Membuat aplikasi berbasis data yang dapat memberikan informasi mengenai pemasukan atau pengeluaran masjid dan lokasi Yayasan yang menerima dana sumbangan dari masjid. Dengan dibuatnya aplikasi ini maka pencapaian yang diharapkan yaitu :

- Dapat mengetahui pihak mana yang berhak namun belum menerima sumbangan dari masjid

- Dana sumbangan masjid dapat dibagikan secara merata

- Masyarakat dapat mengetahui kemana dana hasil infaq dan sedekah dialokasikan

c. System Definition

Dalam pembuatan proyek ini adalah dengan menggunakan sistem informasi berbasis aplikasi/web. Indikator performansi yang akan meningkat jika proyek ini sudah diterapkan adalah :

- Banyak masjid yang akan bekerja sama dengan aplikasi amal tracker

- Pihak penerima sumbangan dapat dengan mudah mendapatkan bantuan dana

- Pengguna aplikasi amal tracker akan semakin banyak

\subsection{System Requirement}

a. System Function

Aplikasi Amal tracker merupakan aplikasi system informasi berbasis data yang memiliki fungsi sebagai berikut :

1. Mencatat dan mengumpulkan data dari pemasukan dan pengeluaran masjid

2. Mengumpulkan data Yayasan atau pihak yang berhak menerima sumbangan dari masjid

3. Menampilkan laporan mengenai alokasi dana dari masjid

b. System Feature

Aplikasi amal tracker memiliki fitur sebagai berikut :

1. Aplikasi memiliki data informasi masjid seperti nama, alamat, dan lokasi

2. Aplikasi memiliki data informasi laporan keuangan dari masjid

3. Aplikasi memiliki data informasi penerima sumbangan

c. Acceptance Criteria

Untuk dapat memasukkan data ke aplikasi, hanya bisa dilakukan oleh user yang telah terdaftar. Berikut merupakan kriteria penerimaan dari aplikasi amal tracker :

1. Aplikasi akan meminta pengguna untuk login terlebih dahulu

2. User yang telah login dapat memasukkan data berupa nama masjid, pemasukan atau pengeluaran, jumlah, dan lokasi penerima sumbangan

3. Pengguna aplikasi dapat melihat informasi masjid yang terdaftar

4. Pengguna aplikasi yang lain dapat melihat laporan pemasukan atau pengeluaran masjid dan alokasi dana.

5. Pengguna aplikasi dapat melihat informasi dari penerima sumbangan seperti nama, lokasi, alamat, dan jumlah yang diterima

d. System user level

Aplikasi amal tracker memiliki 3 tingkatan pengguna sebagai berikut :

1. Admin

Merupakan user dengan kedudukan yang paling tinggi dan memiliki semua akses. Bertanggung jawab mengelola aplikasi agar dapat berjalan dengan lancar

2. Contributor

Merupakan user yang telah mengisi data untuk dapat membuat akun di aplikasi.

Setelah login, user dapat memasukkan data informasi kedalam aplikasi

3. Viewer

Merupakan user yang hanya dapat melihat informasi yang ditampilkan oleh informasi tanpa harus login. 


\section{Penjelasan SIngkat Terkait Metode}

Dalam pengembangan aplikasi ini, kami menggunakan metode Waterfall, dikarenakan metode ini relatif mudah dimengerti dan mudah digunakan. Waterfall menekankan pada sebuah desain proses yang berurutan yang dalam prosesnya terlihat seperti aliran air terjun dari proses perancangan konsep, analisis proyek, inisialisasi proyek, desain, pembuatan sistem, testing, implementasi dan perawatan.

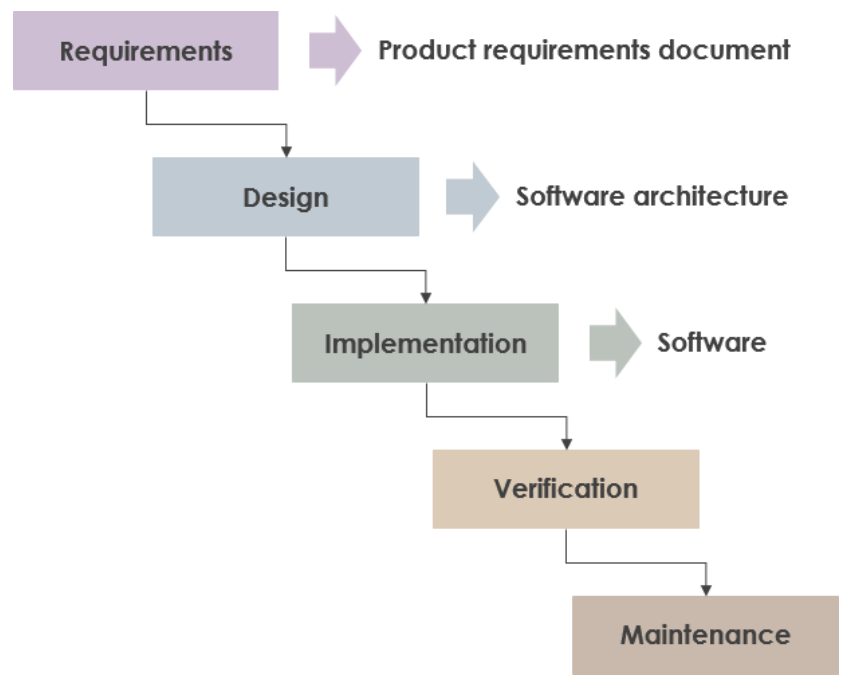

Figure 2 Metode Waterfall

Langkah pertama yang dilakukan adalah identifikasi masalah dan kebutuhan. Kebutuhan bisnis akan diketahui pada tahap ini dan menjadi dasar pada tahap desain. Masalah yang didapat adalah sulitnya mengetahui kemanakah aliran dana dari infaq dan sadaqah masjid. Maka dibuatlah aplikasi yang dapat mengetahui dan melacak aliran dana tersebut. Kemudian dilanjutkan dengan tahap desain basis data. Desain basis data dilakukan dengan penentuan elemen berdasarkan kebutuhan pada proses identifikasi masalah. Pembuatan basis data dilakukan dengan menggunakan bantuan Microsoft access 2016.

\section{Proses Perhitungan}

\subsection{System Design}

1. Stakeholder
a. Owner
:CEO/Admin Amal Tracker
b. User
:Ta'mir/pengurus masjid
c. Customer
: Masyarakat muslim disekitar masjid
d. Analyst : Pengurus masjid

2. User Role
a. Customer
: Melihat data dana aliran sumbangan
b. Sales
: melakukan input data pemasukan/pengeluaran ke aplikasi
c. CEO/admin
: Mensingkronisasi data dan melakukan maintenance

3. Proses Bisnis Eksisting

Pengurus masjid mengelola dana dari infaq dan sedekah dan melakukan pembagian dana namun informasi mengenai aliran dana tidak dibagikan ke masyarakat atau tidak banyak masyarakat yang tau

4. Proses Bisnis Usulan

Pengurus masjid dapat melakukan input data kedalam aplikasi amal tracker, kemudian admin akan melakukan sinkronisasi dengan data pihak penerima sumbangan. Masyarakat dapat melihat hasil laporan dari masjid mengenai persebaran aliran dana dari masjid. 


\subsection{Data Flow Diagram (DFD)}

Berikut merupakan DFD dari aplikasi Amal Tracker DFD level 0

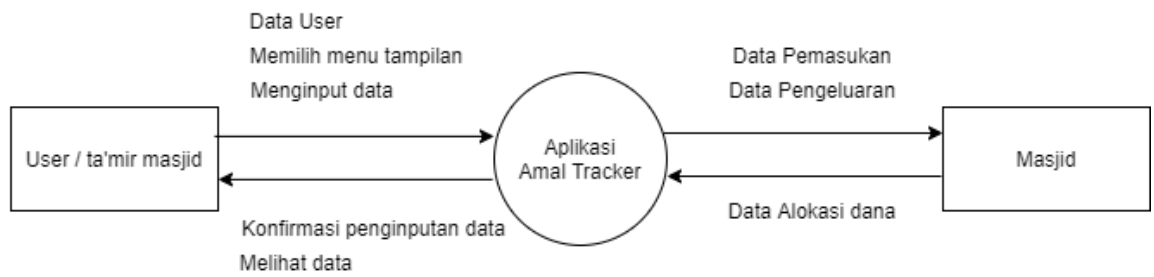

DFD level 1

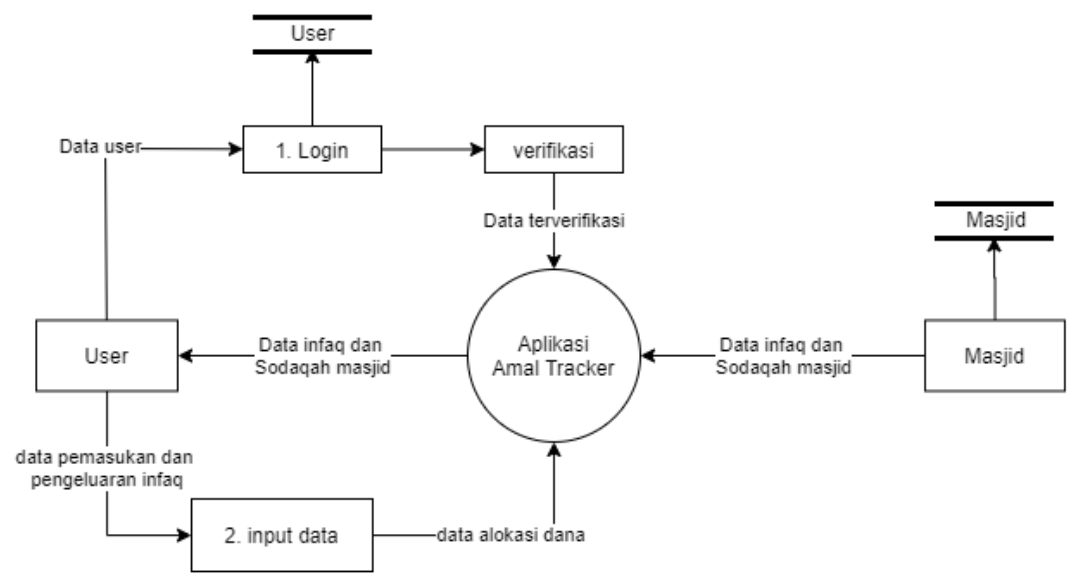

DFD level 2 Login

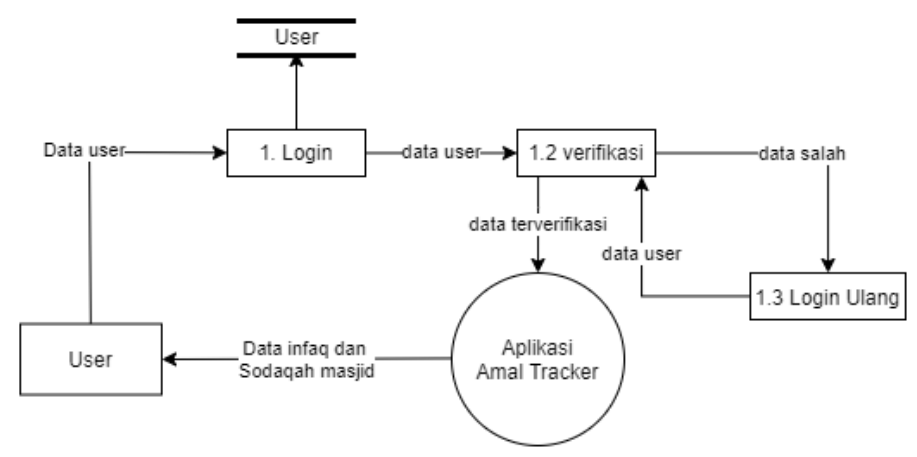

DFD level 2 Input Data

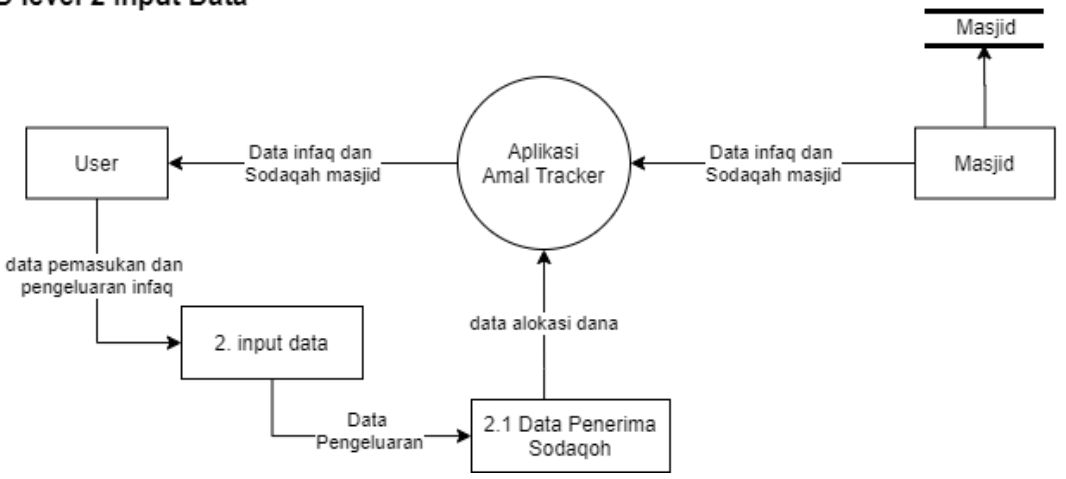

Figure 1 Gambar Data Flow Diagram 


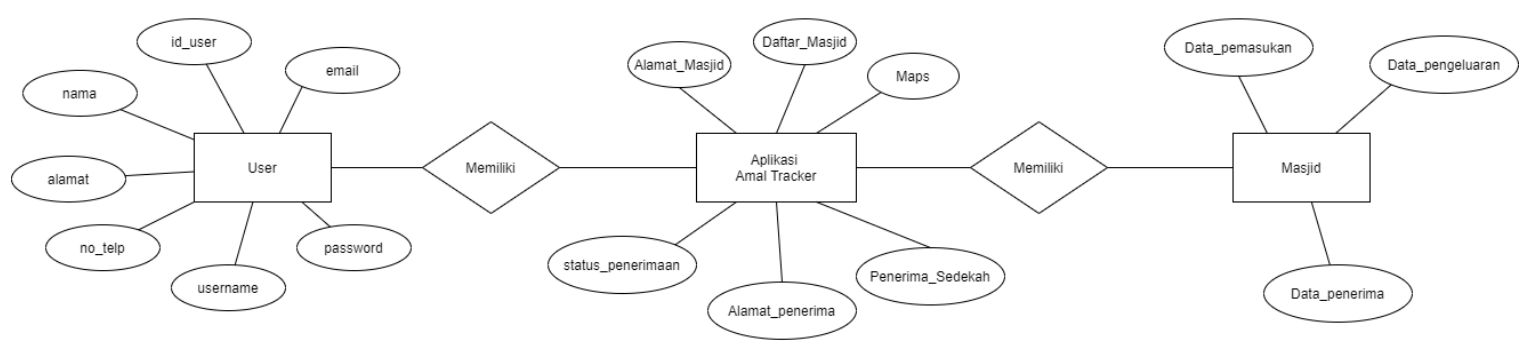

Figure 2 Gambar ERD

\subsection{Database Design}

Berikut merupakan desain database dari aplikasi amal tracker yang dibuat menggunakan Microsoft access 2016

\begin{tabular}{|c|c|c|c|c|c|c|}
\hline \multicolumn{7}{|c|}{ query inputdata $\times$} \\
\hline & id_user & Nama_Ta'mi . & Masjid & Jenis_input & - Lokasi_PeneI & tanggal \\
\hline & ahmad01 & Ahmad & Al-Akbar & Pengeluaran & 3000000 yayasan & $5 / 12 / 2020$ \\
\hline & iqbal12 & Iqbal & Syamsul Ulum & Pengeluaran & 5000000 Panti asuhan & $5 / 20 / 2020$ \\
\hline & irfanmiqbal & irfan & baitussalam & Pemasukan & 2000000 Panti Asuhan & $5 / 14 / 2020$ \\
\hline & yusuf_09 & Yusuf & baitussalam & Pengeluaran & 10000000 yayasan & $5 / 27 / 2020$ \\
\hline * & & & & & 0 & \\
\hline
\end{tabular}

\subsection{Use Case Diagram}

Berikut merupalan Use Case diagram dari aplikasi amal tracker

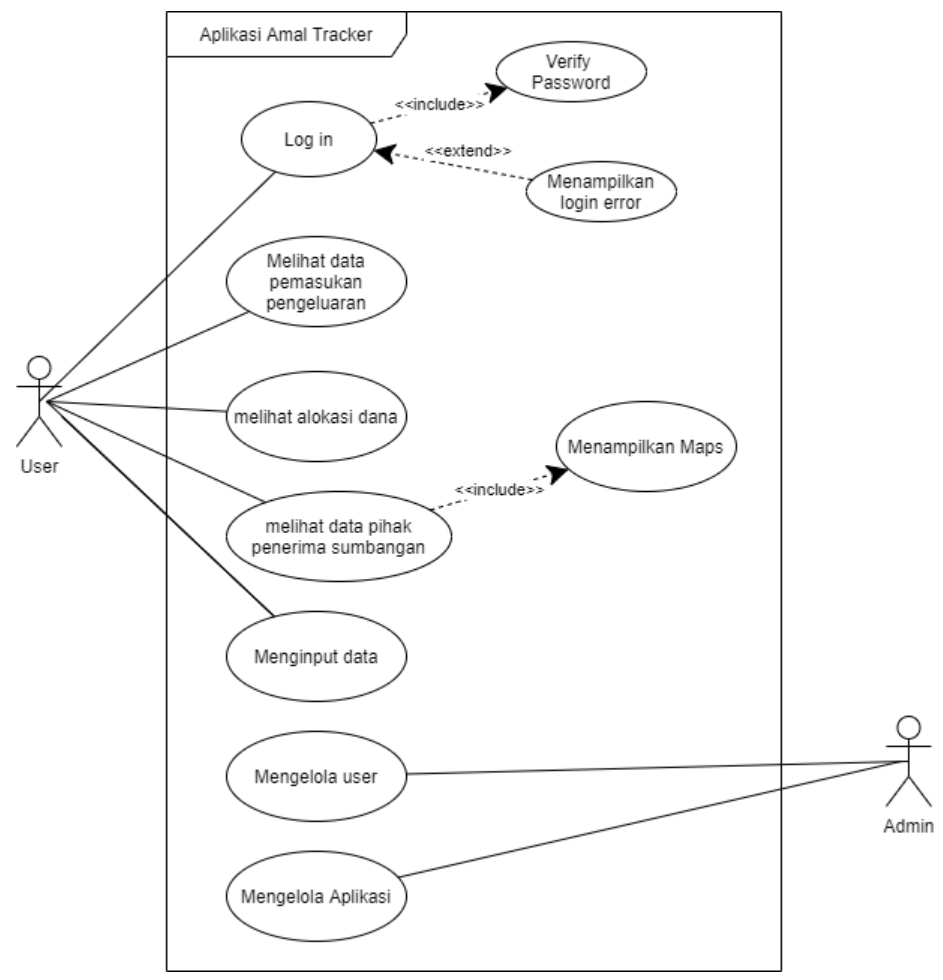

Figure 3 Gambar Use Case Diagram 


\subsection{Activity Diagram}

Berikut merupakan Activity Diagram dari aplikasi amal tracker

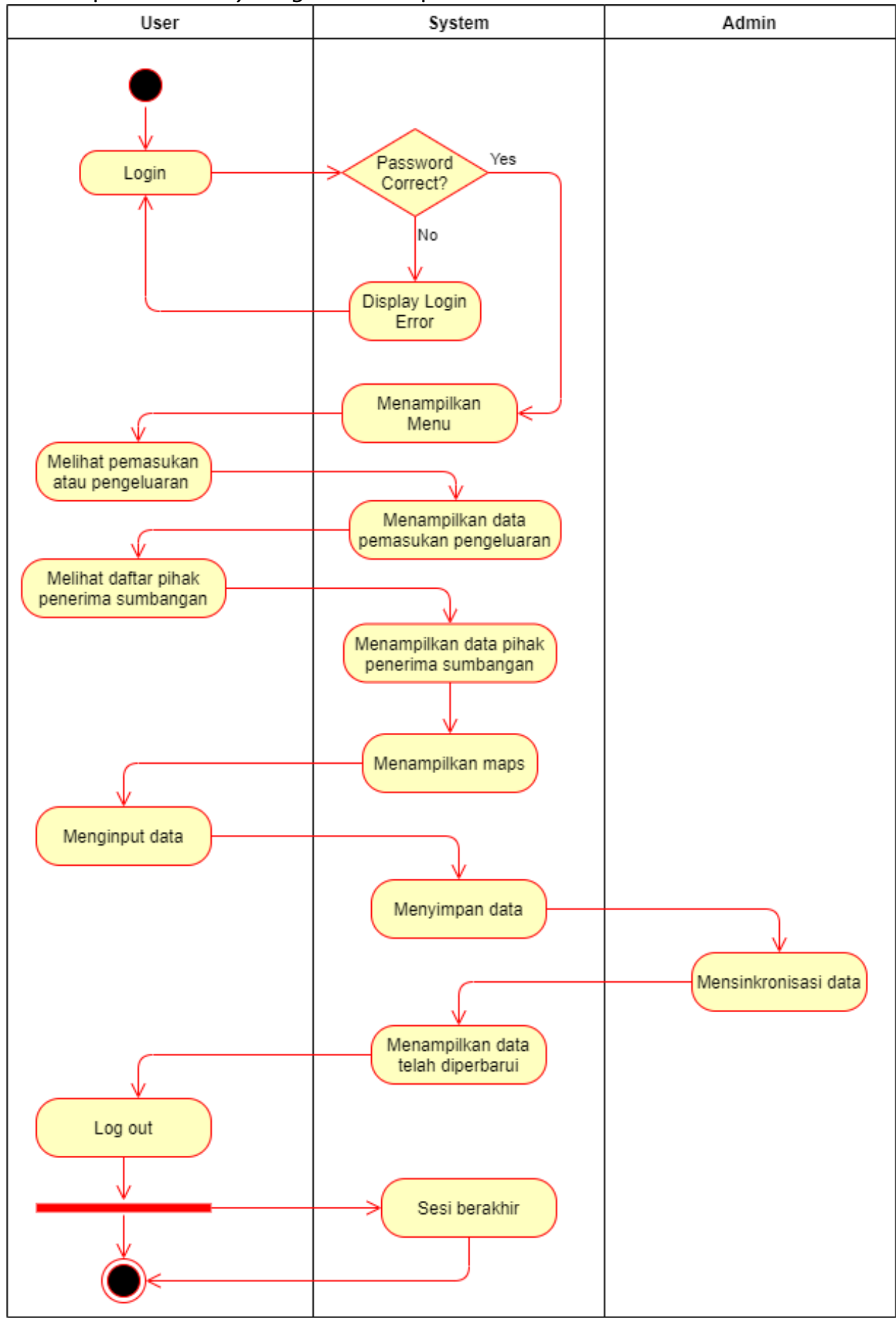

Figure 4 Gambar Activity Diagram

\subsection{Sequence Diagram}

Berikut merupakan sequence diagram dari aplikasi amal tracker 

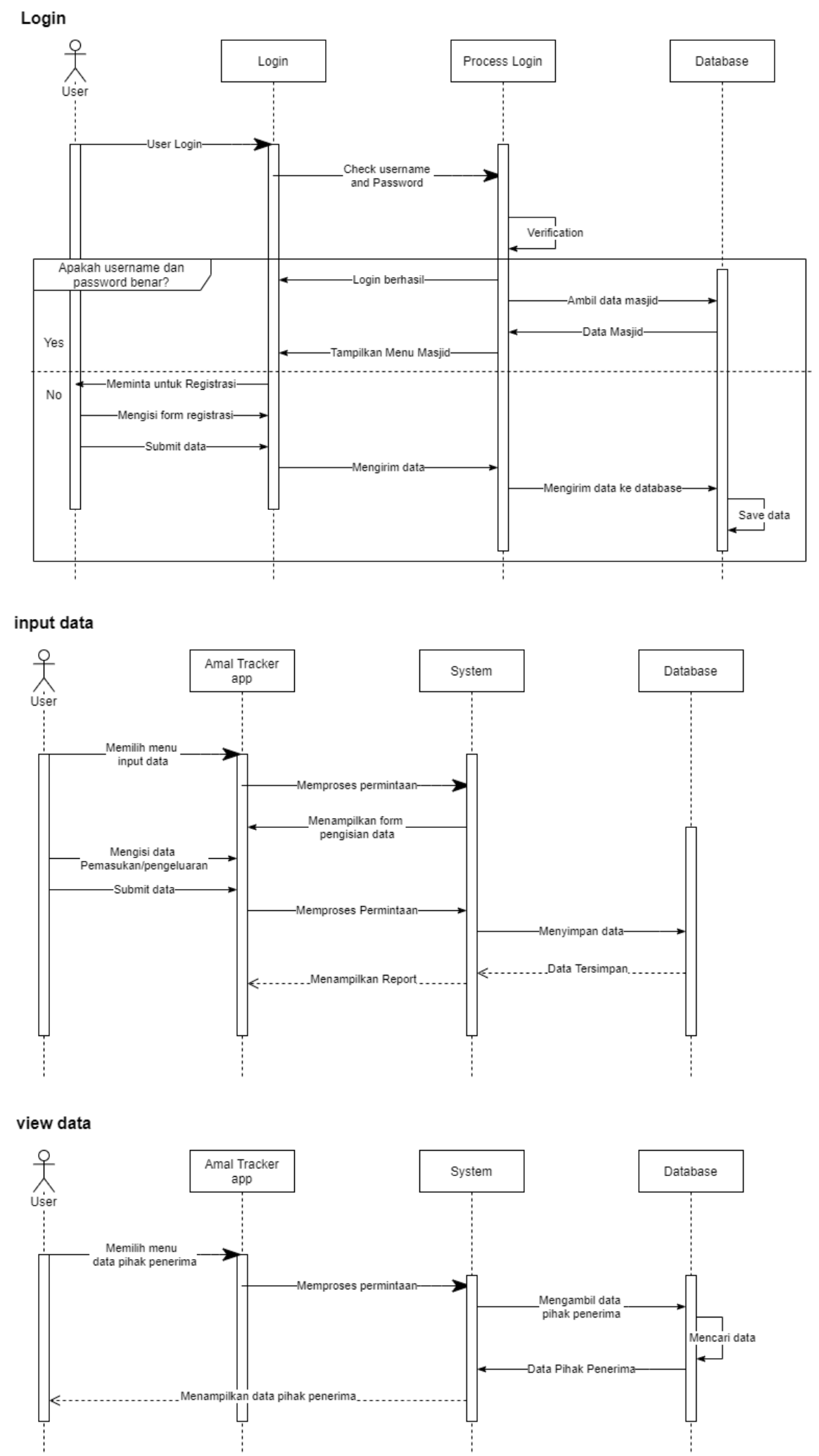

Figure 5 Gambar Sequence Diagram

3.8 Interface Design

Berikut merupakan tampilan interface dari aplikasi amal tracker yang dibuat dengan menggunakan Microsoft Access 2016 


\begin{tabular}{ll|} 
id_user & yusuf_09 \\
Nama_Ta'mir & Yusuf \\
Masjid & baitussalam \\
Jenis_input & Pengeluaran \\
\hline Jumlah & 10000000 \\
\hline Lokasi_Penerima & yayasan \\
\hline tanggal & $5 / 27 / 2020$ \\
\hline & Simpan Baru \\
\hline
\end{tabular}

Figure 6 Gambar Form

\begin{tabular}{|c|c|c|c|c|c|c|}
\hline \multicolumn{7}{|c|}{ Amal info } \\
\hline id_user & Nama_Ta'mir & Masjid & Jenis_input & Jumlah & Lokasi_Penerima & tanggal \\
\hline irfanmiqba & irfan & baitussalam & Pemasukan & 2000000 & Panti Asuhan & $5 / 14 / 2020$ \\
\hline ahmad01 & Ahmad & Al-Akbar & Pengeluaran & 3000000 & yayasan & $5 / 12 / 2020$ \\
\hline iqbal12 & Iqbal & Syamsul Ulum & Pengeluaran & 5000000 & Panti asuhan & $5 / 20 / 2020$ \\
\hline yusuf_09 & Yusuf & baitussalam & Pengeluaran & 10000000 & yayasan & $5 / 27 / 2020$ \\
\hline
\end{tabular}

Friday, May 29, 2020

Page 1 of 1

Figure 7 Gambar Report

\subsection{Source Code}

Berikut merupakan Source code dari aplikasi amal tracker berupa tabel input data

\begin{tabular}{|c|c|c|c|c|c|c|}
\hline \multicolumn{7}{|c|}{ inputdata } \\
\hline & id_user & - Nama_Ta'mi r & Masjid & Jenis_input & - Lokasi_Penel - & tanggal ${ }^{-}$Click to Add \\
\hline & ahmad01 & Ahmad & Al-Akbar & Pengeluaran & 3000000 yayasan & $5 / 12 / 2020$ \\
\hline & iqbal12 & Iqbal & Syamsul Ulum & Pengeluaran & 5000000 Panti asuhan & $5 / 20 / 2020$ \\
\hline & irfanmiqbal & irfan & baitussalam & Pemasukan & 2000000 Panti Asuhan & $5 / 14 / 2020$ \\
\hline & yusuf_09 & Yusuf & baitussalam & Pengeluaran & 10000000 yayasan & $5 / 27 / 2020$ \\
\hline * & & & & & 0 & \\
\hline
\end{tabular}

Figure 8 Gambar Tabel input data 


\section{Penutup}

4.1 Kesimpulan

Aplikasi amal tracker merupakan sebuah solusi bagi pengurus masjid dan para jama'ah untuk dapat mengetahui dan melacak aliran dari dana infaq dan sedekah. Aplikasi amal tracker mencatat pemasukan dan pengeluran dari dana infaq dan sedekah kemudian menyesuaikannya dengan data pihak penerima sumbangan. Dengan ini dana sumbangan dapat diketahui dan dapat tersebar merata. Para jama'ah juga dapat mengetahui kemana aliran dana dari infaq dan sedekah yang mereka sumbangkan

\subsection{Saran}

Untuk penelitian selanjutnya, diharapkan aplikasi ini dapat lebih maksimal penggunaannya, dengan bekerja sama dengan banyak masjid dan menambah fitur baru seperti terintegrasi dengan google maps sehingga informasi yang didapatkan dapat lebih lengkap.

\section{References}

[1] R. Aurachman, "Review Terhadap OSF.IO Sebagai Sarana Publikasi Preprint," OSF Preprints, 17 May 2020.

[2] R. Aurachman, "Kerangka Perancangan Sistem Informasi Sebagai Pembelajaran Mahasiswa Teknik Industri," osf.io, 52020.

[3] Sigit. (2018, September 4). Manajemen Proyek: Waterfall atau Agile? Mana lebih baik? Retrieved from medium.com: https://medium.com/skyshidigital/manajemen-proyek-waterfall-atau-agilemana-lebih-baik-b92901f88159

Additional

[a] R. Aurachman, "Review Terhadap OSF.IO Sebagai Sarana Publikasi Preprint," OSF Preprints, 17 May 2020. doi:10.31219/osf.io/rvumx , Available: https://osf.io rvumx

[b] R. Aurachman, "Kerangka Perancangan Sistem Informasi Sebagai Pembelajaran Mahasiswa Teknik Industri," osf.io, doi:10.31219/osf.io/tmpcn , 5 2020. Available: https://osf.io/tmpcn 